\title{
Wind Turbine Bearing Failure Detection Using Generator Stator Current Homopolar Component Ensemble Empirical Mode Decomposition
}

\author{
Yassine Amirat, Vincent Choqueuse and Mohamed Benbouzid
}

\begin{abstract}
Failure detection has always been a demanding task in the electrical machines community; it has become more challenging in wind energy conversion systems because sustainability and viability of wind farms are highly dependent on the reduction of the operational and maintenance costs. Indeed the most efficient way of reducing these costs would be to continuously monitor the condition of these systems. This allows for early detection of the generator health degeneration, facilitating a proactive response, minimizing downtime, and maximizing productivity. This paper provides then an assessment of a failure detection techniques based on the homopolar component of the generator stator current and attempts to highlight the use of the Ensemble Empirical Mode Decomposition (EEMD) as a tool for failure detection in wind turbine generators for stationary and non stationary cases.
\end{abstract}

Index Terms-Wind turbine, induction generator, bearing failure, ensemble empirical mode decomposition, stator current, homopolar component.

\section{INTRODUCTION}

Wind energy conversion systems (WECS) are the fastestgrowing sources of new electric generation in the world and it is expected to remain so for some time, and those sources are becoming a reliable competitor of classical power generation systems, which are facing to constantly changing operating parameters, such as fuel cost, multiple fuel tradeoffs and maintaining older systems becomes more costly. WECS offer an alternative and emerging solution by deploying wind farms offshore or onshore, where there are substantial wind resources, leading to a best electricity generating opportunities. However, the offshore or onshore environments impose a high demand for reliability on the installed equipment because they are hardly accessible or even inaccessible [1].

\section{A. Wind Turbine Failure Detection Context}

Many techniques and tools have been developed for wind turbine electric generator condition monitoring in order to prolong their life span as reviewed in [2].

Y. Amirat is with ISEN, EA 4325 LBMS, 20, Rue Cuirassé Bretagne, 29200 Brest, France (e-mail: Yassine.Amirat@isen.fr).

V. Choqueuse and M.E.H Benbouzid are with the University of Brest, EA 4325 LBMS, Rue de Kergoat, CS 93837, 29238 Brest, France (e-mail: Vincent.Choqueuse@univ-brest.fr, Mohamed.Benbouzid@univ-brest.fr).
Some of these techniques used the existing and pre-installed sensors, which may measure speed, output torque, vibrations, temperature, flux densities, etc. These sensors are managed together in different architectures and coupled with algorithms to allow an efficient monitoring of the system condition [3]. Those methods have shown their effectiveness in electric motor condition monitoring. From the theoretical and experimental point of view, the well-established methods are: electrical quantities signature analysis (current, power, etc.), vibration monitoring, temperature monitoring and oil monitoring.

In the case of wind turbines, it has been shown that failures in the drive train could be diagnosed from the generator electrical quantities. The advantage of signature analysis of the generator electrical quantities is that those quantities are easily accessible during operation (i.e. the current can be acquired by current transformer or Hall effect device, the voltage via a voltage transformer, and the power by computation). For steady-state operations, the Fast Fourier Transform (FFT), the PSD (Power Spectral Density) and other techniques based upon them, as for example the STFT (Short-Time Fourier Transform), are widely used in the literature [4]. However, in the case of variable speed wind turbines, FFT is difficult to interpret and it is difficult to extract the variation features in time-domain, since the operation is predominately non stationary due the stochastic behavior of the wind speed. To overcome this problem, failure detection procedures based on time-frequency representation (Spectrogram, Quadratic TFR, etc...) or time-scale analysis (wavelet) have been proposed [58]. Nevertheless, these techniques have drawbacks such as high complexity, poor resolution or may suffer from artifacts (cross-terms, etc). Moreover, failure frequencies tracking is not an easy task [9].

\section{B. Bearing Failures Importance}

Since induction machine rotors are under high stresses, including thermal stresses, mechanical stresses, and electrical stresses, they are statistically more vulnerable compared to the stator. Particularly, bearings are the most frequently failed component [10]. Moreover, in the wind power industry context, bearing failures have been a persistent problem which account for a significant proportion of all failures in wind turbines [1]. Bearing failure of WECS generators is the most common failure mode associated with a long downtime.

Bearing failure is typically caused by some misalignment in the drive train, which gives rise to abnormal loading and accelerates bearing wear. Because of their construction, rolling 
element bearings generate precisely identifiable signature on vibration with characteristic frequencies. Those frequencies present an effective route for monitoring progressive bearing degradation. It is therefore possible to detect on the stator side the frequencies associated with the bearings using accelerometers mounted directly on the bearing housing, which is not often easily accessible [11]. Nonintrusive condition monitoring techniques, which monitor the bearing condition using only the generator currents or voltages, are preferred due to their nonintrusiveness and also low cost. To tackle this problem, numerous failure detection techniques have proposed by analyzing the stator side electrical quantities; such as the current [12] or the instantaneous power factor [13].

In this important and particular context, this paper will focus on bearing failure detection. As this failure leads to stator current amplitude modulation [14], it is therefore proposed to assess the efficiency of the Ensemble Empirical Mode Decomposition (EEMD) using the homopolar component of the stator current as a failure detection tool.

\section{FAILURE DETECTION USING ADVANCED SIGNAL PROCESSING TECHNIQUES}

\section{A. Why Monitoring the Homopolar Current?}

This study suggests the use of the homopolar current as the variable to be monitored for failure detection. Indeed, failures majority lead to an obvious unbalance behavior of a threephase machine. This will give rise to a homopolar component of the current. This component could be very useful if the neutral point is connected allowing the use of one current sensors. In a wind turbine application, no homopolar current is produced by the generator (i.e. doubly-fed induction generator) since the neutral point is disconnected. However, the component could be computed and therefore monitored.

The homopolar current is computed through the Clarke transform and is given by

$$
\left[\begin{array}{l}
I_{0} \\
I_{\alpha} \\
I_{\beta}
\end{array}\right]=\sqrt{\frac{2}{3}}\left[\begin{array}{ccc}
\frac{1}{\sqrt{2}} & \frac{1}{\sqrt{2}} & \frac{1}{\sqrt{2}} \\
1 & \frac{-1}{2} & \frac{-1}{2} \\
0 & \frac{\sqrt{3}}{2} & \frac{-\sqrt{3}}{2}
\end{array}\right]\left[\begin{array}{l}
I_{a} \\
I_{b} \\
I_{c}
\end{array}\right]
$$

Where $I_{a, b, c}$ are the three-phase currents. Hence

$$
I_{0}=\frac{1}{\sqrt{3}}\left(I_{a}+I_{b}+I_{c}\right)
$$

\section{B. Current Modulation vs Failure Detection Technique}

Most of electric machine failures lead to current modulation (amplitude and/or phase) [11]. This is the particular case of bearing failures [15]. Indeed, a bearing failure is assumed to produce and air gap eccentricity and hence producing an unbalanced magnetic pull that leads to stator current modulation [16]. In this context, it is a demodulation technique is a well-suited tool for failure detection.

For modulated signals, the most popular techniques are Teager-Kaizer Energy Operator (TKEO) [17], Hilbert Transform (HT) and it has been recently shown that the Concordia Transform (CT) can be used for demodulation [1819]. Those techniques were investigated in many research works for failure detection tasks. However, TKEO is less robust against noise and HT is valid only for mono-component signals, while CT is reliable only for balanced three-phase system. To go besides those constraints, innovative techniques are investigated for tracking the fault component by blind source separation such as Principal Component Analysis (PCA) [20] or noise cancellation [21].

Unfortunately, in typical electric machines, stator current dominant components are the supply fundamental and harmonics, the eccentricity harmonics, the slot harmonics, the saturation harmonics, and other components from unknown sources including environmental noise. These components could be considered as noise in the context of bearing failure detection [21].

Under these considerations, it is proposed to investigate the empirical mode decomposition (EMD) in order to track the dominant component introduced by the bearing failure in the homopolar current.

\section{The EMD Briefly}

The EMD method has recently focused considerable attention and been widely indexed to rotating machinery fault detection [22-23]. The EMD technique is an adaptive timefrequency data analysis method for multi-component, nonlinear and non-stationary signals. It decomposes the signal into a number of Intrinsic Mode Functions (IMFs), each of which is a mono-component function. The multi-components signal (the current $i$ in our case) is then decomposed into $M$ intrinsic modes and a residue $R_{M}$ [24-25].

$$
i(n)=\sum_{m=1}^{M} i m f_{m}(n)+R_{M}(n)
$$

The procedure for extracting the IMFs from a signal is illustrated in Fig. 1.

In addition, the implementation of EMD is a data-driven process, not requiring any pre-knowledge of the signal or the machine. This particular advantage in wind turbines context drive the EMD to be a promising tool for delivering improved condition monitoring [26]. The EMD method has however several drawbacks. The stop criterion, envelope technique, and mode-mixing problem are the most important topics that need to be addressed in order to improve the EMD algorithm [27]. Mode-mixing is the major drawback. Indeed, a detail related to one scale can appear in two different intrinsic modes. This makes an individual IMF devoid of physical meanings. 


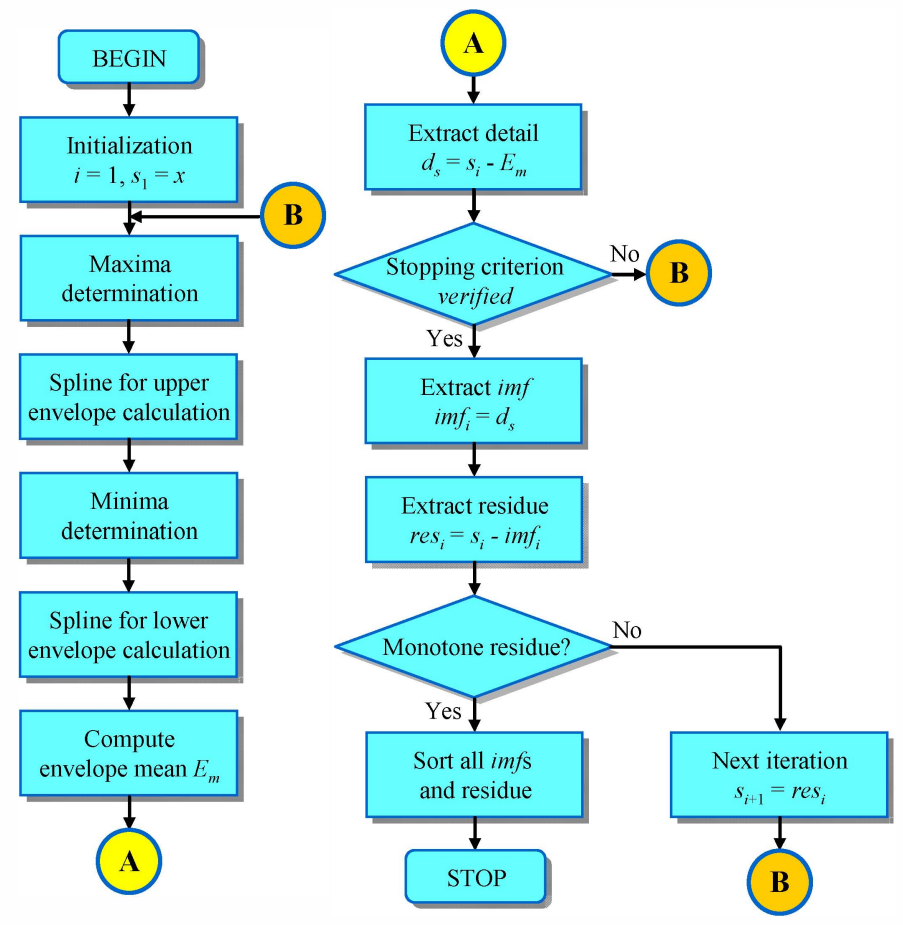

Fig. 1. Flow chart of the EMD process for signal decomposition.

To overcome the mode-mixing problem, the Ensemble EMD (EEMD) was introduced [28].

\section{The EEMD versus the EMD}

The EEMD is a noise-assisted data analysis method. It defines true IMFs as the mean of an ensemble of trials. Each trial consists of the decomposition results of the signal adding a finite amplitude white noise. In this context, it is demonstrated that noise could help data analysis in the EMD method and therefore automatically mitigates mode-mixing [29]. The EEMD procedure for extracting the IMFs from a signal is illustrated in Fig. 2.

The EEMD reliability depends on the choice of the ensemble number $N$ and the noise amplitude $a$. Those two parameters are linked by [29]

$$
e_{n}=\frac{a}{\sqrt{N}}
$$

Where $e_{n}$ is the standard deviation error and is defined as the discrepancy between the input signal and the corresponding imf.

\section{E. What is Specifically Proposed?}

For failure detection several fault detectors based on amplitude demodulation have been proposed in the available literature. However, most of them assume that a training database is available. This can be very difficult to obtain for WECS.

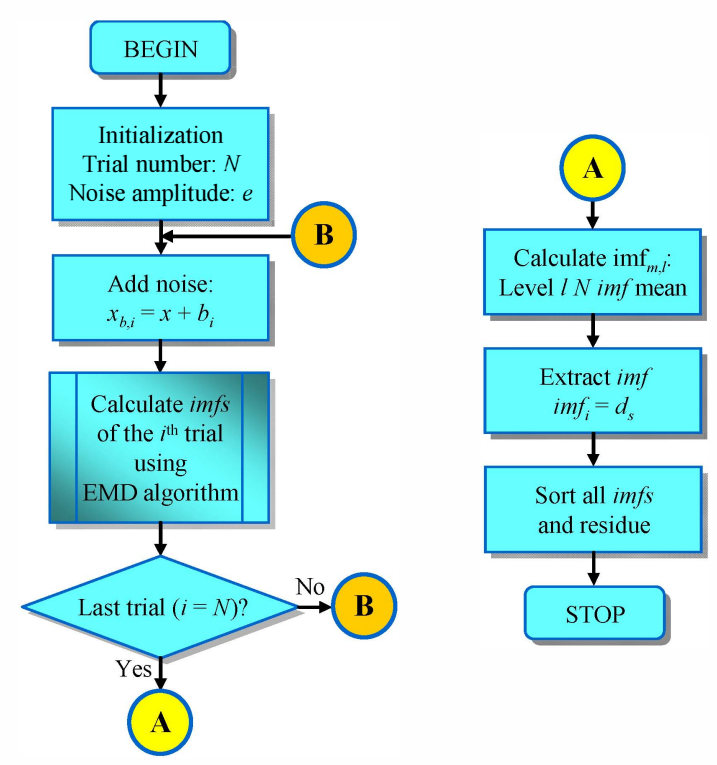

Fig. 2. Flow chart of the EEMD process for signal decomposition.

Indeed, it has been mentioned in a number of previously published paper, that one of the main difficulties in real word testing of developed condition monitoring technique, is the lack of collaboration needed with wind turbine operators and manufacturers, due to data confidentiality, particularly when failures are present [3].

In this paper, the authors propose a low complexity detector which does not require any training sequence. Indeed, the proposed detector is based on the dominant imf variance.

\section{EXPERIMENTAL EVALUATION OF THE EEMD-BASED FAILURE DETECTION APPROACH}

\section{A. Test Facility Description}

The failures are obtained by simply drilling holes in different parts of the bearing (Fig. 3).

A conventional test bed is used in order to test the proposed failure detection method (Fig. 4). The mechanical part (Fig. 7a) is composed by a synchronous and an induction machine. The induction machine is fed by the synchronous generator in order to eliminate time harmonics. Indeed, this will automatically eliminate supply harmonics and therefore allow focusing only on bearing faults effect on the stator current.

The tested induction machine has the following rated parameters: $0.75 \mathrm{~kW}, 220 / 380 \mathrm{~V}, 1.95 / 3.4 \mathrm{~A}, 2780 \mathrm{rpm}, 50$ $\mathrm{Hz}, 2$ poles, Y-connected. It has two 6204.2ZR type bearings with the following parameters: outside diameter is $47 \mathrm{~mm}$, inside diameter is $20 \mathrm{~mm}$, and pitch diameter is $31.85 \mathrm{~mm}$. A bearing has eight balls with an approximate diameter of 12 $\mathrm{mm}$ and a contact angle of $0^{\circ}$.

\section{B. Experimental Tests}

Figures 5 and 6 show the three phase currents and the homopolar component, for healthy and faulty bearings (failure c), respectively. 


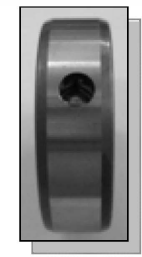

(a)

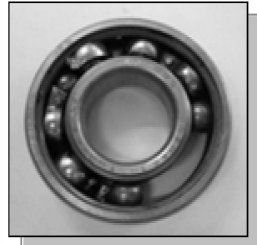

(c)

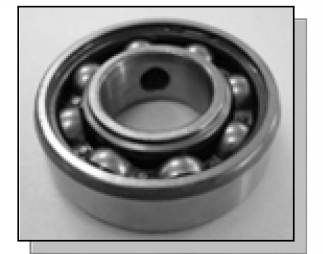

(b)

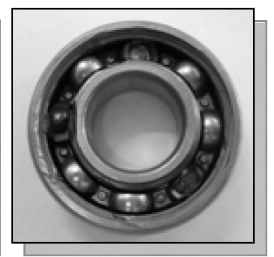

(d)
Fig. 3. Artificially deteriorated bearings: (a) outer race deterioration, (b) inner race deterioration, (c) cage deterioration, (d) ball deterioration.

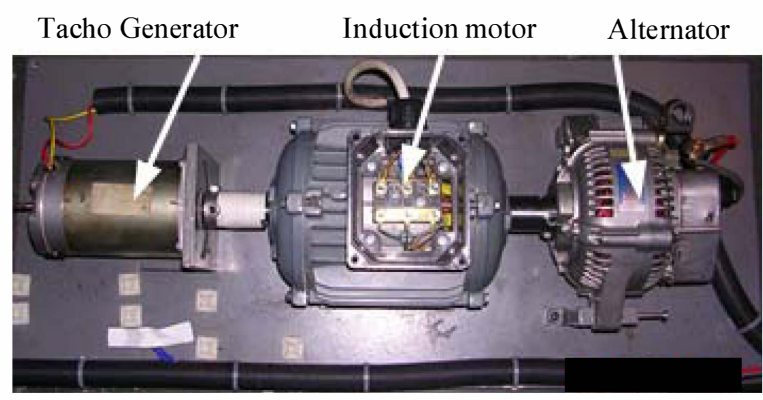

(a) Mechanical part.

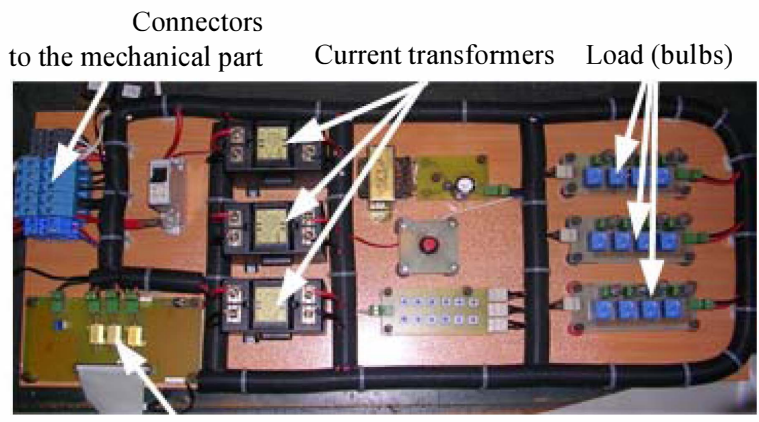

Outlet to DAQ card and PC

(b) Electrical part.

Fig. 4. Experimental setup.

After adjusting the EEMD parameters respectively the noise amplitude $a$ and the ensemble number $N$; the decomposition is applied to the homopolar current computed through (2), for several loads during the induction machine operation with healthy and faulty bearing.

For illustration, Fig. 7 show the current homopolar component first 5 IMFs and the residue when the induction machine is loaded by $40 \%$ of the nominal load.

It seems therefore that in presence of a bearing failure the $4^{\text {th }}$ IMF is more energized. Indeed, strong oscillations are observed. This is clearly illustrated by Fig. 8 .

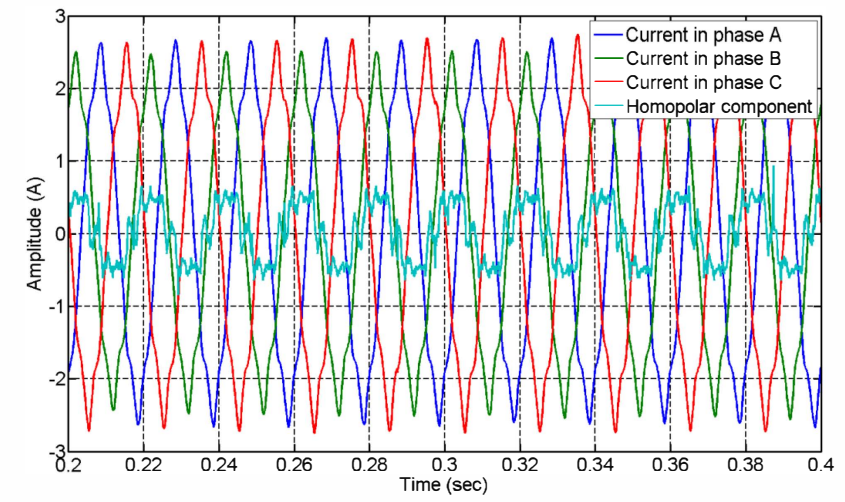

Fig. 5. The healthy case currents

(the homopolar component is multiplied by 20).

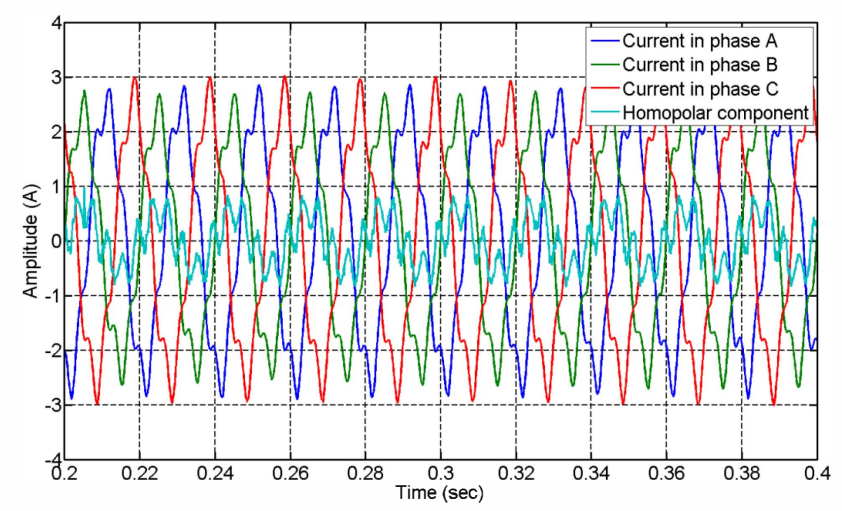

Fig. 6. The faulty case (failure c) currents (the homopolar component is multiplied by 20 ).

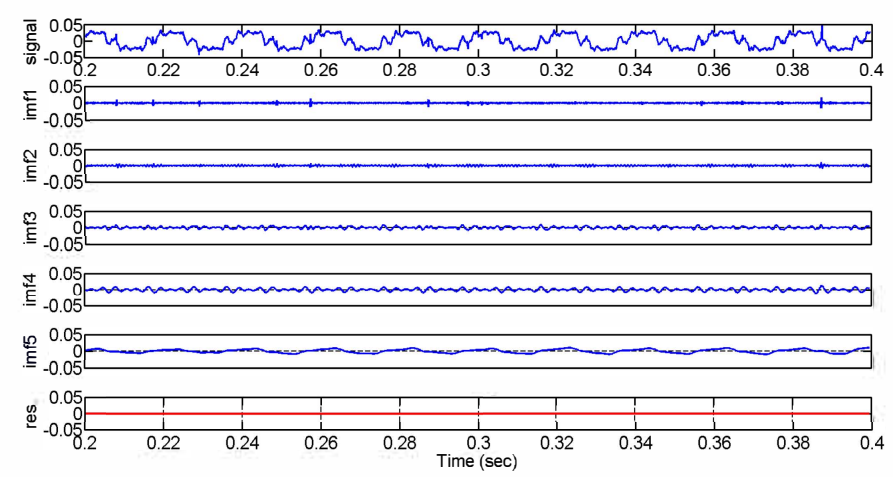

(a) Healthy bearings.

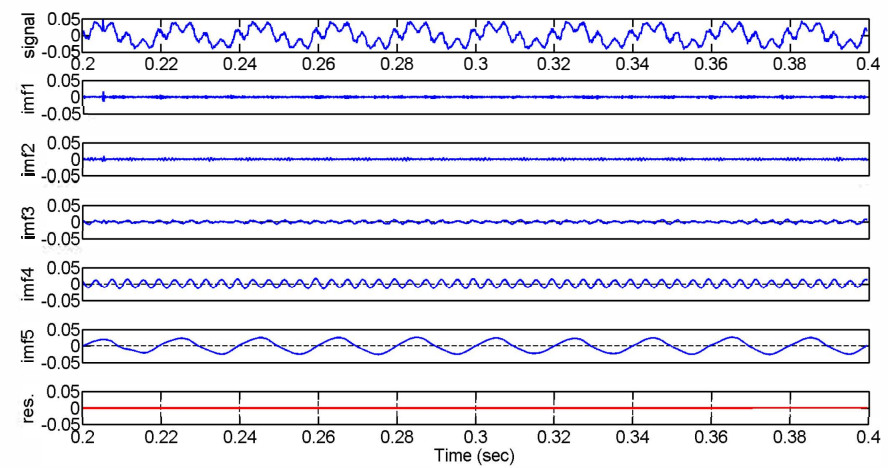

(b) Faulty bearings (failure c).

Fig. 7. Current homopolar component EEMD decomposition. 


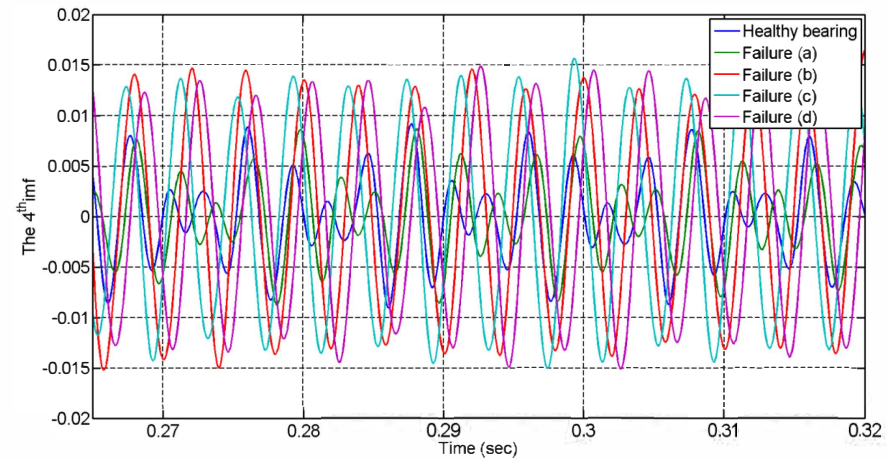

Fig. 8. Current homopolar component $4^{\text {th }}$ IMF for healthy and faulty bearings.

In order to quantify those oscillations, the statistical variance $\sigma^{2}$ of this IMF is computed for all the failures for several loads using the following equation

$\sigma_{i m f_{4}}^{2}=\frac{1}{N} \sum_{n=0}^{N-1}\left[i m f_{4}(n)-\mu_{i m f_{4}}\right]^{2}$

where $\mu_{i m f 4}$ is $i m f_{4}(n)$ mean.

The obtained results are summarized by Table 1 and Fig. 9 . It should be first mentioned that the variance is not strictly equal to zero for healthy bearing.

Table 1. Current homopolar component $4^{\text {th }}$ IMF variance.

\begin{tabular}{|c|c|c|c|c|c|}
\hline \hline & \multicolumn{5}{|c|}{$\sigma^{2}$} \\
\hline \hline Load & $\begin{array}{c}\text { Healthy } \\
\text { bearing }\end{array}$ & $\begin{array}{c}\text { Failure } \\
\text { (a) }\end{array}$ & $\begin{array}{c}\text { Failure } \\
(\mathrm{b})\end{array}$ & $\begin{array}{c}\text { Failure } \\
(\mathrm{c})\end{array}$ & $\begin{array}{c}\text { Failure } \\
(\mathrm{d})\end{array}$ \\
\hline $00.00 \%$ & $2.20 \mathrm{E}-05$ & $\mathbf{1 . 3 0 E}-05$ & $7.02 \mathrm{E}-05$ & $7.04 \mathrm{E}-05$ & $7.48 \mathrm{E}-05$ \\
\hline $26.66 \%$ & $1.58 \mathrm{E}-05$ & $\mathbf{1 . 4 6 E - 0 5}$ & $7.53 \mathrm{E}-05$ & $7.55 \mathrm{E}-05$ & $7.22 \mathrm{E}-05$ \\
\hline $40.00 \%$ & $1.77 \mathrm{E}-05$ & $\mathbf{1 . 5 9 E}-05$ & $9.05 \mathrm{E}-05$ & $8.83 \mathrm{E}-05$ & $8.82 \mathrm{E}-05$ \\
\hline $53.33 \%$ & $2.45 \mathrm{E}-05$ & $\mathbf{2 . 2 1 E - 0 5}$ & $1.07 \mathrm{E}-04$ & $1.10 \mathrm{E}-04$ & $1.14 \mathrm{E}-04$ \\
\hline \hline
\end{tabular}

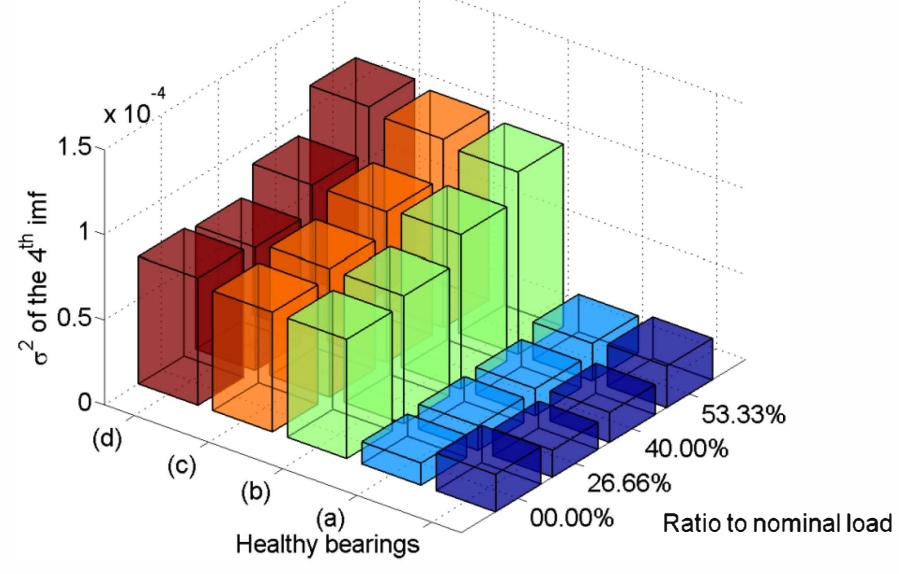

Fig. 9. Current homopolar component $4^{\text {th }}$ IMF variance for healthy and faulty bearings.
This could be simply explained by the induction machine natural unbalances in one hand and in another hand by the fact that stator current could contain unknown noises. However when a bearing failure occurs, this criteria is multiplied by about 5 . These results clearly demonstrate that the $4^{\text {th }}$ IMF can be used an effective indicator for bearing health monitoring. The exception is failure (a), which needs further investigations in regard to artificially created failures. Table 2 confirms the achieved tendencies.

Table 2. Current homopolar component $4^{\text {th }}$ IMF variance error.

\begin{tabular}{|c|c|c|c|c|}
\hline \hline & \multicolumn{4}{|c|}{$e_{v}=\frac{\left(\sigma_{\text {imf_faulty }}^{2}-\sigma_{\text {imf_healthy }}^{2}\right)}{\sigma_{\text {imf_healthy }}^{2}}$} \\
\hline \hline Load & Failure (a) & Failure (b) & Failure (c) & Failure (d) \\
\hline $00.00 \%$ & $\mathbf{4 1 \%}$ & $218 \%$ & $219 \%$ & $239 \%$ \\
\hline $26.66 \%$ & $\mathbf{8 \%}$ & $375 \%$ & $377 \%$ & $356 \%$ \\
\hline $40.00 \%$ & $\mathbf{1 0 \%}$ & $413 \%$ & $400 \%$ & $400 \%$ \\
\hline $53.33 \%$ & $\mathbf{1 0 \%}$ & $337 \%$ & $351 \%$ & $366 \%$ \\
\hline \hline
\end{tabular}

\section{CONCLUSION}

This paper dealt with induction machine bearing failures detection using the current homopolar component. This component is first decomposed into intrinsic mode functions through the EEMD which is the EMD free mixed mode version. It was then found that the $4^{\text {th }}$ IMF is the most energized mode. This mode was then analyzed using a statistical criterion on experimental data. The achieved results clearly demonstrate that the $4^{\text {th }}$ IMF can be used an effective indicator for bearing health monitoring.

The obtained results seem very promising for wind turbines monitoring using the generator current. Indeed, the proposed EEMD-based and low complexity failure detector does not require any training database.

\section{REFERENCES}

[1] Y. Amirat, M. Benbouzid, E. Al-Ahmar, B. Bensaker, and S. Turri, "A brief status on condition monitoring and fault diagnosis in wind energy conversion systems," Renewable and Sustainable Energy Reviews, vol. 13, no. 9, pp. 2629-2636, 2009.

[2] B. Lu, Y. Li, X. Wu and Z. Yang, "A review of recent advances in wind turbine condition monitoring and fault diagnosis", in Proceedings of the 2009 IEEE PEMWA, Lincoln (USA), pp. 1-7, June 2009.

[3] W. Yang, P.J. Tavner, C.J. Crabtree and M. Wilkinson, "Cost-effective condition monitoring for wind turbines," IEEE Trans. Industrial Electronics, vol. 57, n¹, pp. 263-271, January 2010.

[4] M. Benbouzid, "A review of induction motors signature analysis as a medium for faults detection," IEEE Trans. Industrial Electronics, vol. 47, no. 5, pp. 984-993, October 2000.

[5] J. Antonino-Daviu, M. Riera-Guasp, M. Pineda-Sanchez, and R.B. Perez, "A critical comparison between DWT and Hilbert-Huang-based methods for the diagnosis of rotor bar failures in induction machines," IEEE Trans. Industry Applications, vol. 45, ${ }^{\circ} 5$, pp. 1794-1803, September/October 2009.

[6] S. Rajagopalan, J. A. Restrepo, J. Aller, T. Habetler, and R. Harley, "Non stationary motor fault detection using recent quadratic time 
frequency representations," IEEE Trans. Industry Applications, vol. 44, n³, pp. 735-744, May/June 2008.

[7] J. Cusido, L. Romeral, J.A. Ortega, J.A. Rosero and A.G. Espinosa "Fault detection in induction machines using power spectral density in wavelet decomposition," IEEE Trans. Industrial Electronics, vol. 55, no. 2, pp. 633-643, February 2008.

[8] M. Blodt, D. Bonacci, J. Regnier, M. Chabert, and J. Faucher, "On-line monitoring of mechanical faults in variable-speed induction motor drives using the Wigner distribution," IEEE Trans. Industrial Electronics, vol. 55, n², pp., 522-533, February 2008.

[9] E.H. El Bouchikhi, V. Choqueuse, M.E.H. Benbouzid, J.F Charpentier and G. Barakat, "A comparative study of time-frequency representations for fault detection in wind turbine," in Proceedings of the 2011 IEEE IECON, Melbourne (Australia), pp. 3584-3589, November 2011.

[10] P. Zhang; Y. Du; T.G. Habetler and B. Lu, "A survey of condition monitoring and protection methods for medium-voltage induction motors," IEEE Trans. Industry Applications, vol. 47, n¹, pp. 34-46, January/February 2011.

[11] P.J. Tavner, "Review of condition monitoring of rotating electrical machines," IET Electric Power Applications, vol. 2, n 4 , pp. 215-247, July 2008 .

[12] F. Immovilli, A. Bellini, R. Rubini and C. Tassoni, "Diagnosis of bearing faults in induction machines by vibration or current signals: A critical comparison," IEEE Trans. Industry Applications, vol. 46, $\mathrm{n}^{\circ} 4$, pp. 1350-1359, July/August 2010.

[13] A. Ibrahim, M. El Badaoui, F. Guillet and F.; Bonnardot, "A New bearing fault detection method in induction machines based on instantaneous power factor," IEEE Trans. Industrial Electronics, vol. 55, $\mathrm{n}^{\circ} 12$, pp.4252-4259, December 2008.

[14] Y. Amirat, V. Choqueuse and M.E.H. Benbouzid, "Condition monitoring of wind turbines based on amplitude demodulation," in Proceedings of the 2010 IEEE ECCE'10, Atlanta (USA), pp. 2417-2421, September 2010.

[15] J.R. Stack, R.G. Harley and T.G. Habetler, "An amplitude modulation detector for fault diagnosis in rolling element bearings," IEEE Trans. Industrial Electronics, vol. 51, n5, pp. 1097-1102, October 2004.

[16] L. Frosini and E. Bassi, "Stator current and motor efficiency as indicators for different types of bearing fault in induction motor," IEEE Trans. Industrial Electronics, vol. 57, n ${ }^{\circ}$, pp. 244-251. January 2010.

[17] I. Kamwa, A.K. Pradhan and G. Joos, "Robust detection and analysis of power system oscillations using the Teager-Kaiser energy operator," IEEE Trans. Power Systems, vol. 26, nº1, pp. 323-333, February 2011.
[18] B. Trajin, M. Chabert, J. Regnier, and J. Faucher, "Hilbert versus Concordia transform for three phase machine stator current timefrequency monitoring," Mechanical systems \& signal processing, vol. 23, nº, pp. 2648-2657, November 2009

[19] I.Y. Önel and M.E.H. Benbouzid, "Induction motor bearing failure detection and diagnosis: Park and Concordia transform approaches comparative study," IEEE/ASME Trans. Mechatronics, vol. 13, n², pp. 257-262, April 2008

[20] V. Choqueuse, M.E.H. Benbouzid, Y. Amirat and S. Turri, "Diagnosis of three-phase electrical machines using multidimensional demodulation techniques," IEEE Trans. Industrial Electronics, vol. 59, issue 4, pp. 2014-2023, April 2012.

[21] W. Zhou, T.G. Habetler and R.G. Harley, "Bearing fault detection via stator current noise cancellation and statistical control," IEEE Trans. Industrial Electronics, vol. 55, nº 4, pp. 4260-269, December 2008.

[22] R. Ricci and P. Pennacchi, "Diagnostics of gear faults based on EMD and automatic selection of intrinsic mode functions," Mechanical Systems and Signal Processing, vol. 25, n³, pp. 821-838, April 2011.

[23] J.A. Rosero, L. Romeral, J.A. Ortega and E. Rosero, "Short-circuit detection by means of empirical mode decomposition and Wigner-Ville distribution for PMSM running under dynamic condition," IEEE Trans. Industrial Electronics, vol. 56, $\mathrm{n}^{\circ} 11, \mathrm{pp} .4534-4547$, November 2009.

[24] Q. Gao, C. Duan, H. Fan and Q. Meng, "Rotating machine fault diagnosis using empirical mode decomposition," Mechanical Systems and Signal Processing, vol. 22, n5, pp. 1072-1081, July 2008.

[25] Y. Amirat, V. Choqueuse and M.E.H. Benbouzid, "Bearing fault detection in DFIG-based wind turbines using the first intrinsic mode function," in Proceedings of the 2010 ICEM, Rome (Italy), pp. 1-6, September 2010.

[26] W. Yang, R. Court, P.J. Tavner and C.J. Crabtree, "Bivariate empirical mode decomposition and its contribution to wind turbine condition monitoring," Journal of Sound and Vibration, vol. 330, n ${ }^{\circ}$, pp. 37663782, July 2011.

[27] X. Hu, S. Peng and W.-L. Hwang, "EMD revisited: A new understanding of the envelope and resolving the mode-mixing problem in AM-FM signals," IEEE Trans. Signal Processing, vol. 60, n³, pp. 1075-1086, March 2012.

[28] Y. Lei, Z. He and Y. Zi, "Application of the EEMD method to rotor fault diagnosis of rotating machinery," Mechanical Systems and Signal Processing, Vol. 23, n 4, pp. 1327-1338, May 2009.

[29] Z.H. Wu and N.E. Huang, "Ensemble empirical mode decomposition: A noise-assisted data analysis method", Advances in Adaptive Data Analysis, vol. 1, n 1, pp. 1-41, 2009. 